\section{Prognostic factors of patients admitted in a medical intermediate care unit: a prospective observational study}

Liliana Fernandes ${ }^{1}$, Sofia Duque1, Joana Silvestre ${ }^{2}$, Patrícia Freitas ${ }^{1}$, Marta Pinto', Alice Sousa ${ }^{1}$, Vítor Batalha1, Luís Campos ${ }^{1}$

1 Medical Intermediate Care Unit, Medicine Department 4, São Francisco Xavier Hospital, Occidental Lisbon Hospital Centre, Lisbon, Portugal

\section{Abstract}

Purpose: Medical Intermediate Care Units (IntCU's) are high-dependency units intended for treatment of patients who do not meet criteria for admission to intensive care units (ICU's) but require a higher level of care than that provided on a general ward. Our purpose was to identify prognostic factors of patients admitted in IntCU.

Materials and Methods: A prospective observational study was performed during 32 months in an IntCU of a central hospital. Main objective was evaluation of mortality and analysis of comorbidity, functional status, acute illness severity and nurse workload as prognostic factors.

Results: Two hundred and eighty-eight patients were included. IntCU and in-hospital mortality was 9,38 and $17,71 \%$, respectively. All the scores applied, concerning comorbidity, functional status, acute illness severity and nurse workload were significantly associated to mortality. Simplified Acute Physiology Score II (SAPS II) was the better predictor of mortality followed by Nursing Activities Score (NAS).

Conclusions: Acute illness severity and nursing workload scores validated in ICU are useful and reliable in IntCU setting, being SAPS II and NAS the strongest predictors of mortality. Comorbidity, functional status and age were also prognostic factors. A comprehensive assessment of patients admitted in IntCU is mandatory to reliably predict outcome.
2 Polivalent Intensive Care Unit, São Francisco Xavier Hospital, Occidental Lisbon Hospital Centre, Lisbon, Portugal

\section{Contact information:}

Liliana Fernandes

”- lili.gil.fernandes@gmail.com

\section{Keywords}

medical intermediate care unit, mortality, prognostic factors 


\section{Background}

Medical Intermediate Care Units (IntCU's) are high-dependency units intended for the treatment of unstable patients who do not meet the criteria for admission to intensive care units (ICU's) but require a higher level of care than that provided on a general ward [1]. IntCU's operate as transitional unit [2], working as a step-down unit of patients from ICU[3,4] and as step-up unit of patients from general wards or emergency department [4].

Several authors have showed that a substantial proportion of patients routinely admitted to the ICU's are at low risk of receiving exclusive ICU active interventions such as life support measures [5-12]. The limited and high-cost critical care resources resulted in development of IntCU's[3, 7, 13], ruling out from ICU setting those low-risk patients admitted in intensive care for monitoring or those already recovering, not requiring full intensive care[6, 14, 15]. Therefore, IntCU's permit a better resource utilization[16] and optimization of scarce intensive care beds available [14, 15, 17-21], though ensuring patients continuous monitoring and specialized medical and nursing care. Consequently, IntCU shortens length of stay in ICU [14], remaining a higher number of ICU beds available for critically ill patients dependent on intensive care specific procedures and life support techniques. Some studies revealed that treatment of patients carried out in IntCU is less expensive $[2,4,22-29]$ than in ICU, being IntCU a cost-effective alternative to treat low-risk critical patients [3, 30].

On the other hand IntCU's may relieve the general medicine ward of the most unstable patients [15]. Some authors have also suggested that chronically critically ill patients who might not benefit of intensive care should be managed in alternative places to ICU[25, 27, 31], such as IntCU's.

Clinical effectiveness of IntCU's has also been demonstrated. Continuous monitoring carried out in IntCU permits early identification of physiologi- cal deterioration, before organ dysfunction occurs, and timely intervention, avoiding need for ICU admission [4, 32] and improving outcome [21]. As a step-down unit IntCU might also improve outcome of patients discharged from ICU $[21,33]$ as some deaths may occur following premature discharge to general wards unable to provide the level of care still necessary to a recovering patient. Consequently, some authors have found that IntCU's prevented ICU readmissions and reduced hospital mortality. $[33,34,56]$. IntCU's also improve patient and family satisfaction as its physical environment is less agressive than the ICU [1].

Several studies have focused on prognostic factors of patients admitted in ICU's, demonstrating utility of severity scores as prognostic factors [3540]. However, very few studies were performed in IntCU's [41-43, 56]. Some authors suggested using ICU specific acute illness severity scores to identify low-risk patients eligible to IntCU's [8, 44, 45]. So far there are no specific severity scores for intermediate care, and efficiency of intensive care severity scores has not been fully established in intermediate care setting.

The primary aim of this study was evaluation of mortality and analysis of acute illness severity, nurse workload, comorbidity and previous functional status as prognostic factors of patients admitted to a medical intermediate care unit.

\section{Methods}

This study was a prospective, single center, observational study conducted during a 32 months period in the Medical Intermediate Care Unit (IntCU) of São Francisco Xavier Hospital. São Francisco Xavier Hospital is a central and university hospital of Lisbon, that belongs to a Hospital Centre of 900 beds, serving a population of about 935.000 people as a tertiary referral center.

The IntCU is a 4-bed unit that mainly admits 
Figure 1: Flow diagram of patients included and their outcome

\section{7 patients}

admitted in IntCU

during 32 months

89 patients excluded $n=89$

\section{8 patients} enrolled

27 patients died in IntCU

261 patients survived IntCU stay

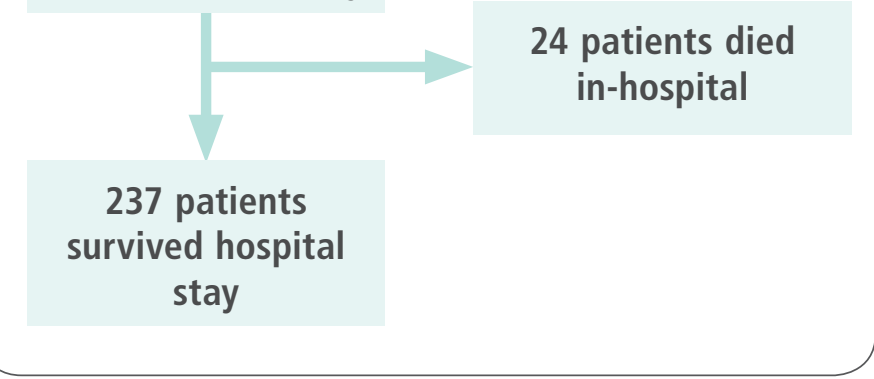

medical patients from the emergency department, from medical and surgical wards and from the intensive care unit.

During 32 months (April 2008-December 2010) 377 patients were admitted in the IntCU (mean age $67.1 \pm 19.3$ years, mortality $10,6 \%$ ). Two hundred and eighty eight patients were enrolled to this study, excluded those with data incomplete and those who stayed in the IntCU for a period of less than 24 hours (Figure 1).

Patients data were recorded in a database including age, gender, previous functional status, previous comorbidity, length of stay, primary diagnosis on admission, severity of acute illness, nurse workload and outcome. All data were obtained using standardized instruments.

\section{Previous Functional Status}

The previous functional status was determined applying the Barthel index of basic activities of daily living (BADL)[46], classifying patients as independent, slightly dependent, moderately dependent, highly or totally dependent in BADL, according to the number of basic care skills in which patients require physical assistance. Information was obtained directly through interview to patient and/or caregiver and clinical records of the origin departments.

\section{Previous Comorbidity}

Comorbidity was determined applying the Charlson comorbidity index[47], which is an instrument performed to predict 10-year mortality in longitudinal studies, according to comorbid diseases that patient presents. Existence of comorbid conditions was assessed through research of previous hospital archives and/or interview to patient and/or caregiver.

\section{Primary Diagnosis}

Fifteen categories of primary diagnosis were established: Heart Failure, Arrhythmias, Myocardial infarction or ischemia, Pulmonary Thromboembolism, Pulmonary Disease, Sepsis, Neurological disease, Hepatic Disease, Metabolic or Endocrinologic disease, Digestive bleeding, other Gastroenterologic Disease, Intoxication, Pancreatitis, Kidney Diseases and Others.

\section{Severity of Acute IIIness}

Severity of acute illness was determined applying intensive care scores: Acute Physiology and Chronic Health Evaluation II (APACHE II)[37], the Simplified Acute Physiology Score II (SAPS II)[35] and the Sequential Organ Failure Assessment (SOFA)[41], which were calculated in the first 24 hours of admission. The main purpose of these three scores is to stratify patients according to in-hospital mortality risk and higher scores represent higher mortality risk. 


\section{Nursing Workload}

Nursing workload, which can be an indicator of illness severity, was measured through two intensive care scores: Therapeutic Intervention Scoring System-28 (TISS-28)[48] and the Nursing Activities Score (NAS) [49], which were calculated in the first 24 hours of admission. IntCU nurse: patient ratio in daytime was 0,5 .

\section{Outcome}

The main outcome was mortality in the IntCU and the secondary one was in-hospital mortality. In-hospital mortality was obtained reviewing hospital electronic records. According outcome, two groups of patients were established: Survivors and Non-Survivors.

\section{Statistical analysis}

Continuous variables were expressed as mean \pm standard deviation, median and $95 \%$ confidence interval (IC) for the median. Comparison of continuous variables between Survivors and Non-Survivors was performed using the $T$ test. Non-parametric Test (Kruskal Wallis) was used to compare differences between independent multiple groups, such as NAS variation concerning origin of patients:

Bivariate and multiple logistic regression with forwards stepwise selection were used to identify prognostic factors of IntCU and in-hospital mortality. The entry criterion for the multivariate model was $p \leq 0,05$. The receiver operating characteristics (ROC) area under the curve (AUC) was used to assess models discrimination.

Tests were two-tailed and reported statistically significant at $p<0,05$.

SPSS version 18 was used to statistical analysis.

\section{Results}

A total of 288 patients were enrolled. Main baseline characteristics of patients enrolled in this study are resumed in table 1 . The mean age was $65,67 \pm 20,38$ years-old and $62,5 \%$ were female. The main sources of admissions were the emergency department $(50,3 \%)$, ICU $(20,5 \%)$ and medical wards $(16,7 \%)$. The main primary diagnosis at admission were pulmonary disease $(28,2 \%)$, heart failure $(20,6 \%)$ and sepsis $(11,1 \%)$. The mean Charlson Index score was 5,49 $\pm 3,57$ points, corresponding to high comorbidity. The mean pre-admission Barthel Index score was $82,38 \pm 29,58$, demonstrating that most patients presented only mild dependency in basic activities of daily living. The mean APACHE II, SAPS II and SOFA scores were 14,79 $\pm 6,84,31,85 \pm$ $11,70,5,13 \pm 2,31$ points, respectively, corresponding to mean predicted mortality that range from 10 to $25 \%$, according the acute illness severity score. The main destinations were the wards (92\%) and discharge $(30,6 \%)$.

Comparison of patients enrolled in this study was performed according to their outcome: Survivors $(n=237)$ and Non Survivors ( $n=51)$ (Table 1).

Survival was significantly associated to younger age, lower comorbidity, better functional status, lower acute illness severity and nursing workload.

The origin of these patients can be a bias for survival once the authors rejected the hypothesis that there is an equal distribution of NAS according to origin $(p=0.003)$. The most significant difference of NAS variation was between outpatient clinic and others (non ICU, emergency department or medical ward). Concerning these last three departments, medical ward presented the worst mean of NAS and so the necessity of a higher nurse:patient ratio for these patients (Figure 2).

No statistically significant differences were observed between IntCU and in-hospital non-survivors.

The overall mortality was $17,71 \%$ (9,38\% in IntCU and $8,33 \%$ after IntCU discharge). Mean length of stay in IntCU was 10,18 \pm 9,07 days. These data are presented in table 2 . 
Table 1. Main baseline characteristics of patients

\begin{tabular}{|c|c|c|c|c|}
\hline & $\begin{array}{c}\text { Total } \\
n=288\end{array}$ & $\begin{array}{c}\text { Survivors } \\
n=237\end{array}$ & $\begin{array}{l}\text { Non-Survivors } \\
\qquad n=51\end{array}$ & $p^{1}$ \\
\hline \multicolumn{5}{|l|}{ Age (years) } \\
\hline Mean \pm SD & $65,67 \pm 20,38$ & $63,55 \pm 21,00$ & $75,53 \pm 13,47$ & \\
\hline $95 \% \mathrm{Cl}$ & $63,31-68,04$ & $60,87-66,24$ & $71,74-79,32$ & $<0,001$ \\
\hline Median & 72,0 & 71,0 & 77,0 & \\
\hline \multicolumn{5}{|c|}{ Comorbidity - Charlson Index } \\
\hline Mean $\pm S D$ & $5,49 \pm 3,57$ & $4,95 \pm 3,42$ & $7,94 \pm 3,18$ & \\
\hline $95 \% \mathrm{Cl}$ & $5,07-5,90$ & $4,51-5,39$ & $7,05-8,84$ & $<0,001$ \\
\hline Median & 6,00 & 5,00 & 8,00 & \\
\hline \multicolumn{5}{|c|}{$\begin{array}{l}\text { Pre-admission basic activities of daily living } \\
\text { Barthel index }\end{array}$} \\
\hline Mean \pm SD & $82,38 \pm 29,58$ & $85,38 \pm 27,84$ & 68,02 & \\
\hline $95 \% \mathrm{Cl}$ & $78,89-85,88$ & $81,77-89,00$ & $58,29-77,76$ & $<0,001$ \\
\hline Median & 100 & 100 & 77,5 & \\
\hline \multicolumn{5}{|c|}{ Acute IIIness Severity } \\
\hline \multicolumn{5}{|c|}{ APACHE II } \\
\hline Mean $\pm S D$ & $14,79 \pm 6,84$ & $13,66 \pm 6,52$ & $20,04 \pm 5,84$ & \\
\hline $95 \% \mathrm{Cl}$ & $13,99-15,58$ & $12,82-14,49$ & $18,40-21,68$ & $<0,001$ \\
\hline Median & 14,00 & 13,0 & 20,0 & \\
\hline \multicolumn{5}{|l|}{ SAPS ॥ } \\
\hline Mean $\pm S D$ & $31,85 \pm 11,70$ & $29,78 \pm 11,15$ & $41,49 \pm 9,17$ & \\
\hline $95 \% \mathrm{Cl}$ & $30,49-33,21$ & $28,35-31,20$ & $38,91-44,07$ & $<0,001$ \\
\hline Median & 32,00 & 31,0 & 41,0 & \\
\hline \multicolumn{5}{|l|}{ SOFA } \\
\hline Mean $\pm S D$ & $5,13 \pm 2,31$ & $4,81 \pm 2,18$ & $6,63 \pm 2,34$ & \\
\hline $95 \% \mathrm{Cl}$ & $4,86-5,40$ & $4,53-5,09$ & $5,97-7,29$ & $<0,001$ \\
\hline Median & 5,00 & 4,50 & 7,00 & \\
\hline \multicolumn{5}{|l|}{ Nursing Workload } \\
\hline \multicolumn{5}{|l|}{ TISS-28 } \\
\hline Mean \pm SD & $21,84 \pm 6,21$ & $21,20 \pm 6,02$ & $24,82 \pm 6,29$ & \\
\hline $95 \% \mathrm{Cl}$ & $21,11-22,56$ & $20,43-21,97$ & $23,03-26,61$ & $<0,001$ \\
\hline Median & 21,00 & 20,0 & 24,0 & \\
\hline \multicolumn{5}{|l|}{ NAS } \\
\hline Mean $\pm S D$ & $53,51 \pm 16,99$ & $50,85 \pm 15,03$ & 66,01 & \\
\hline $95 \% \mathrm{Cl}$ & $51,53-55,49$ & $48,92-52,78$ & $60,32-71,70$ & $<0,001$ \\
\hline Median & 48,80 & 46,20 & 65,70 & \\
\hline
\end{tabular}

Continues $\gg>>$ 


\begin{tabular}{|c|c|c|c|c|}
\hline & $\begin{array}{c}\text { Total } \\
n=288\end{array}$ & $\begin{array}{c}\text { Survivors } \\
n=237\end{array}$ & $\begin{array}{c}\text { Non-Survivors } \\
\qquad n=51\end{array}$ & $p^{1}$ \\
\hline \multicolumn{5}{|l|}{ Primary Diagnosis (n, \%) } \\
\hline Heart Failure & $59 / 20,5$ & $45 / 19,1$ & $14 / 27,5$ & \\
\hline Arrhythmias & $5 / 1,7$ & $4 / 1,7$ & $1 / 2,0$ & \\
\hline Myocardial infarction or ischemia & $11 / 3,8$ & $9 / 3,8$ & $2 / 3,9$ & \\
\hline Pulmonary Thromboembolism & $19 / 6,6$ & $16 / 6,8$ & $3 / 5,9$ & \\
\hline Pulmonary Disease & $81 / 28,1$ & $67 / 28,4$ & $14 / 27,5$ & \\
\hline Sepsis & $32 / 11,1$ & $26 / 11,0$ & $6 / 11,8$ & \\
\hline Neurological disease & $7 / 2,4$ & $6 / 2,5$ & $1 / 2,0$ & \\
\hline Hepatic Disease & $2 / 0,7$ & $1 / 0,4$ & $1 / 2,0$ & \\
\hline Metabolic or Endocrinologic disease & $15 / 5,2$ & $15 / 6,4$ & $0 / 0$ & \\
\hline Digestive bleeding & $6 / 2,1$ & $5 / 2,0$ & $1 / 2,0$ & \\
\hline Other Gastroenterologic Disease & $3 / 1,0$ & $0 / 0$ & $3 / 5,9$ & \\
\hline Intoxication & $9 / 3,1$ & $8 / 3,4$ & $1 / 2,0$ & \\
\hline Pancreatitis & $11 / 3,8$ & $11 / 4,7$ & $0 / 0$ & \\
\hline Kidney Diseases & $9 / 3,1$ & $8 / 3,4$ & $1 / 2,0$ & \\
\hline Others & $19 / 6,5$ & $16 / 6,4$ & $3 / 5,9$ & \\
\hline
\end{tabular}

Figure 2: NAS distribution according to origin department

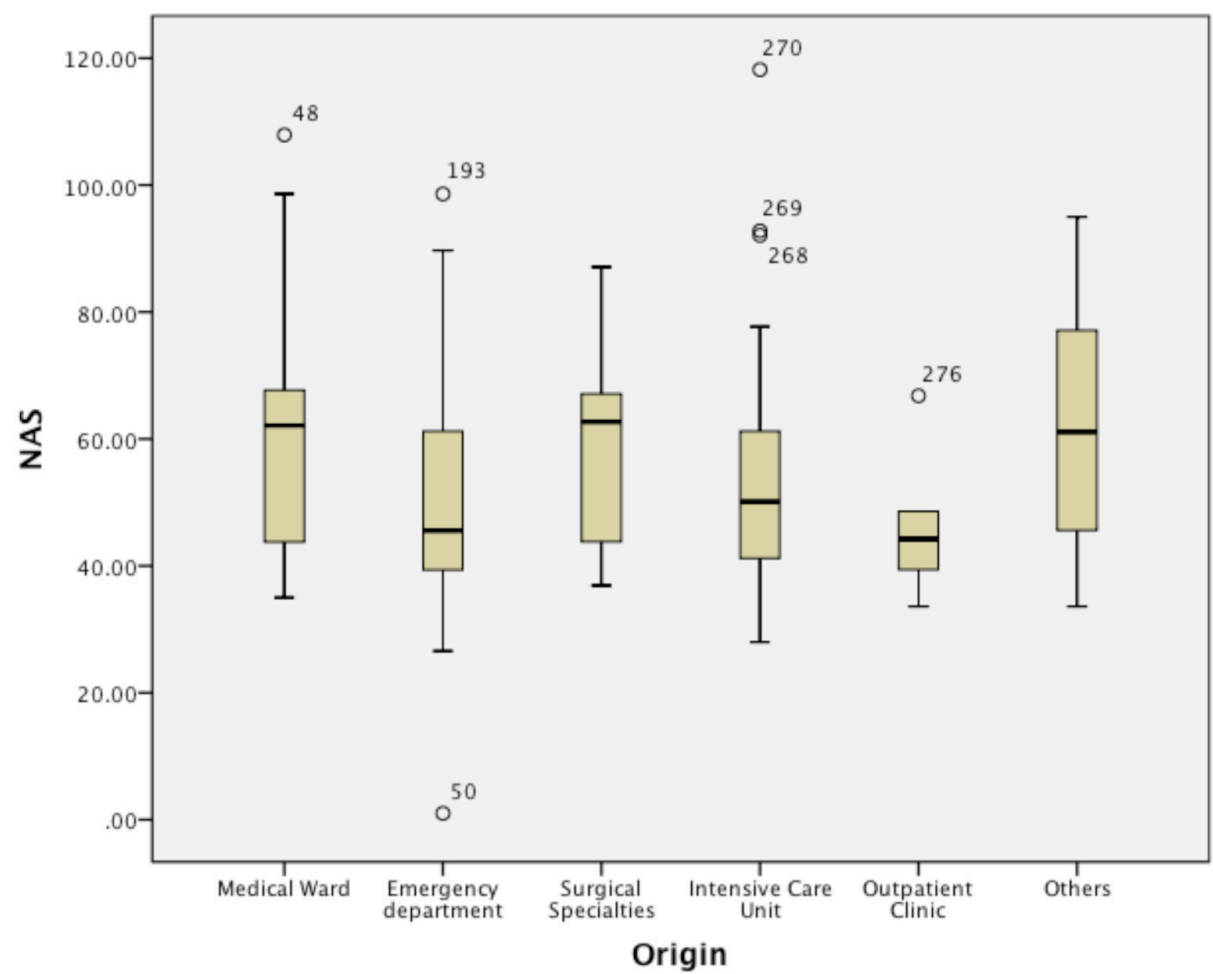


Table 2. Outcomes

\begin{tabular}{|c|c|}
\hline \multicolumn{2}{|c|}{ Length of stay (days) } \\
\hline Mean+SD & $10,18 \pm 9,07$ \\
\hline $95 \% \mathrm{Cl}$ & $\mathbf{9 , 1 3}-\mathbf{1 1 , 2 3}$ \\
\hline Median & $\mathbf{7 , 0}$ \\
\hline IntCU mortality (n, \%) & $\mathbf{2 7 / 9 , 3 8 \%}$ \\
\hline In-hospital mortality (n, \%) & $\mathbf{5 1 / 1 7 , 7 1 \%}$ \\
\hline
\end{tabular}

Bivariate logistic regression analysis (Table 3) revealed that Charlson index, the three acute illness severity scores, and the two nursing workload scores applied were associated with IntCU and in-hospital mortality. Barthel index revealed to be a protective factor for death. Age was also associated to both IntCU and in-hospital mortality, though it was a weaker mortality predictor compared to acute illness severity, comorbidity and functional status.

Table 3. Results of the bivariate and multiple logistic regression analyses (OR odds ratio)

\begin{tabular}{|c|c|c|c|}
\hline Predictors & OR $(95 \% \mathrm{Cl})$ & p & AUC $(95 \% \mathrm{Cl})$ \\
\hline \multicolumn{4}{|l|}{ Bivariated Logistic Regression } \\
\hline \multicolumn{4}{|l|}{ IntCU Mortality } \\
\hline Charlson Index & $1,248(1,112-1,400)$ & $<0,001$ & $0,710(0,615-0,805)$ \\
\hline Barthel Index & $0,981(0,970-0,992)$ & $=0,001$ & $0,689(0,574-0,804)$ \\
\hline APACHE ॥ & $1,151(1,083-1,224)$ & $<0,001$ & $0,771(0,574-0,804)$ \\
\hline SAPS ॥ & $1,151(1,067-1,166)$ & $<0,001$ & $0,813(0,734-0,892)$ \\
\hline SOFA & $1,320(1,133-1,538)$ & $<0,001$ & $0,727(0,639-0,816)$ \\
\hline TISS-28 & $1,115(1,047-1,186)$ & $=0,001$ & $0,705(0,612-0,798)$ \\
\hline NAS & $1,052(1,029-1,077)$ & $<0,001$ & $0,705(0,651-0,840)$ \\
\hline Age & $1,039(1,010-1,069)$ & $=0,007$ & $0,654(0,555-0,752)$ \\
\hline \multicolumn{4}{|l|}{ In-hospital mortality } \\
\hline Charlson Index & $1,285(1,164-1,418)$ & $<0,001$ & $0,736(0,668-0,803)$ \\
\hline Barthel Index & $0,984(0,975-0,993)$ & $<0,001$ & $0,673(0,586-0,759)$ \\
\hline APACHE ॥ & $1,151(1,095-1,210)$ & $<0,001$ & $0,769(0,709-0,830)$ \\
\hline SAPS ॥ & $1,114(1,074-1,154)$ & $<0,001$ & $0,787(0,722-0,852)$ \\
\hline SOFA & $1,373(1,201-1,569)$ & $<0,001$ & $0,728(0,654-0,802)$ \\
\hline TISS-28 & $1,094(1,042-1,149)$ & $<0,001$ & $0,669(0,590-0,747)$ \\
\hline NAS & $1,051(1,032-1,071)$ & $<0,001$ & $0,729(0,654-0,805)$ \\
\hline Age & $1,039(1,018-1,060)$ & $<0,001$ & $0,657(0,584-0,731)$ \\
\hline \multicolumn{4}{|l|}{ Multiple Logistic Regression } \\
\hline IntCU Mortality & & & $0,826(0,749-0,903)$ \\
\hline SAPS ॥ & $1,094(1,041-1,149)$ & $<0,001$ & \\
\hline NAS & $1,036(1,009-1,063)$ & $=0,008$ & \\
\hline In-hospital Mortality & & & $0,811(0,751-0,871)$ \\
\hline SAPS $\|$ & $1,096(1,055-1,139)$ & $<0,001$ & \\
\hline NAS & $1,039(1,016-1,062)$ & $=0,001$ & \\
\hline
\end{tabular}


Multiple logistic regression revealed that SAPS II and NAS were the strongest predictors of IntCU and in-hospital mortality and both models showed good discriminant performance (AUC 0,826, 95\% Cl: 0,749-0,903; AUC 0,811, 95\% Cl: 0,751-0,871, respectively).

\section{Discussion}

This study revealed that outcome of patients admitted in IntCU depends on several factors, such as previous functional status, comorbidity, acute illness severity and also age. To classify each variable we applied scores validated in other levels of care, as tools specific of intermediate care are inexistent.

Previous functional status was inversely associated to mortality, being higher independence in BADL a protective factor for death (odds-ratio (OR) 0,981 $(0,970-0,992), p=0,001)$, similarly to data presented by Torres et al[43]. Previous studies in Medical Wards and ICU revealed that functional impairment is a predictive factor of mortality [50].

We also found that the Charlson comorbidity Index was a significant predictor of IntCU mortality (OR 1,248 (1,112-1,400), $p<0,001)$.

Our results revealed that acute illness severity and nursing workload scores validated in intensive care setting are also good mortality predictors in intermediate care setting. Indeed, all the scores applied were significantly associated to mortality.

Concerning the acute illness severity scores, SAPS II revealed to be the strongest predictor of both IntCU and in-hospital mortality $(p<0,001)$. Previous studies in IntCU have already suggested that SAPS II was reliable to assess severity of illness of patients admitted to an IntCU [41]. We believe that better performance of SAPS II in prediction of IntCU mortality, in comparison to APACHE II and SOFA, might be explained by integration of distinct clinical data in the score, including not only age and data related to organ dysfunction but also previous diseases generally associated to poor outcome, such as neoplastic diseases.

Regarding the nursing workload scores, both NAS and TISS-28 revealed to be good predictor of outcome, but NAS appeared to be superior to TISS-28. Previous studies have reported TISS-28 as a predictor of short-term mortality in IntCU [43] and a potential tool to differentiate between ICU and high-dependency unit patients [51].

Our results revealed a lower IntCU mortality $(9,38 \%)$ than that predicted by SAPS II, as the mean score obtained corresponds to a predicted mortality of about 15\%. Nevertheless, in-hospital mortality was similar to that predicted by SAPS II. Porath et al [30] have conducted a similar study and have found identical in-hospital mortality $(17,6 \%$ vs $17,71 \%$ in our study) though mean APACHE II $(12,9)$ and TISS $(12,6)$ were lower than ours.

Unlike previous studies [52], age revealed to be a predictor of outcome in IntCU, though the weaker one among all the other variables we have studied.

Focusing on multiple logistic regression analysis we might consider that among the variables we have studied the strongest mortality predictor was SAPS II, followed by NAS.

Limitations of our study are mainly related to a relatively small sample size and being a single-centre study. Multicentric studies in intermediate care setting are difficult to perform because of lack of standardization of structure and procedures performed and heterogeneity of patients admitted. Bias might be introduced concerning topics inquired to caregivers or preadmission-related, namely previous functional status $[53,54]$. Nevertheless, all data obtained were statistically significant.

\section{Conclusions}

We consider that our data demonstrate the importance of several variables in patient outcome, 
including not only acute physiologic variables but also previous comorbidity and functional status.

Our results establish the usefulness and reliability of acute illness severity scores validated in ICU in predicting mortality of patients admitted to intermediate care units.

Identification of prognostic factors of IntCU patients is necessary to appropriate and reasonable selection of patients that would benefit from admission in IntCU. Otherwise, absence of admission criteria in IntCU may lead to overutilization of IntCU beds, similar to that observed in ICU setting [3].

Consequently, a comprehensive assessment of patients admitted in IntCU is mandatory to reliably predict their outcome, as previously described[43]. According our results we believe that a possible standard admission assessment would include the SAPS II and NAS calculated in the first 24 hours of admission, the Barthel and Charlson Indexes. Age might be considered a prognostic factor, though inferior than other scores applied.

Nonetheless, we believe that individual patient decisions should not be standardized and exclusively based on scores. Indeed, previous studies have revealed limited usefulness of scores in taking individual patient decisions [40], and clinical judgement should not be substituted for physiological scores[55]. Instead, scores should help and support the individual clinical decision.

Future studies should focus on development of assessment tools integrating physiologic variables, comorbidity and previous functional status, in order to support individual patient decisions. In addition, an effort should be made to implement multicentric studies including similar centers, rather than single-center.

\section{References}

1. Nasraway SA, Cohen IL, Dennis RC, Howenstein MA, Nikas DK, Warren J et al Guidelines on admission and discharge for adult intermediate care units. American College of Critical Care Medicine of the Society of Critical Care Medicine. Crit Care Med 1998, 26(3):607-610.

2. Ridley SA, Intermediate care, possibilities, requirements and solutions. Anaesthesia 1998, 53(7):654-664.

3. Popovich J, Jr., Intermediate care units. Graded care options. Chest 1991, 99(1):4-5.

4. Thompson FJ, Singer M, High dependency units in the UK: variable size, variable character, few in number. Postgrad Med J 1995, 71(834):217-221.

5. Wagner DP, Knaus WA, Draper EA, Identification of low-risk monitor admissions to medical-surgical ICUs. Chest 1987, 92(3):423-428.

6. Zimmerman JE, Wagner DP, Knaus WA, Williams JF, Kolakowski $D$, Draper EA, The use of risk predictions to identify candidates for intermediate care units. Implications for intensive care utilization and cost. Chest 1995, 108(2):490-499.

7. Guidelines for intensive care unit admission, discharge, and triage. Task Force of the American College of Critical Care Medicine, Society of Critical Care Medicine. Crit Care Med 1999, 27(3):633-638

8. Henning RJ, McClish D, Daly B, Nearman H, Franklin C, Jackson $D$, Clinical characteristics and resource utilization of ICU patients: implications for organization of intensive care. Crit Care Med 1987, 15(3):264-269.

9. Knaus WA, Wagner DP, Draper EA, Lawrence DE, Zimmerman JE, The range of intensive care services today. JAMA 1981, 246(23):2711-2716.

10. Rosenthal GE, Sirio CA, Shepardson LB, Harper DL, Rotondi AJ, Cooper GS, Use of intensive care units for patients with low severity of illness. Arch Intern Med 1998, 158(10):1144-1151.

11. Kilpatrick $A$, Ridley S, Plenderleith $L$, A changing role for intensive therapy: is there a case for high dependency care? Anaesthesia 1994, 49(8):666-670.

12. Oye RK, Bellamy PE, Patterns of resource consumption in medical intensive care. Chest 1991, 99(3):685-689.

13. Bone RC, Balk RA, Noninvasive respiratory care unit. A cost effective solution for the future. Chest 1988, 93(2):390-394.

14. Byrick RJ, Power JD, Ycas JO, Brown KA, Impact of an intermediate care area on ICU utilization after cardiac surgery. Crit Care Med 1986, 14(10):869-872. 
15. Franklin CM, Rackow EC, Mamdani B, Nightingale S, Burke $\mathrm{G}$, Weil $\mathrm{MH}$, Decreases in mortality on a large urban medical service by facilitating access to critical care. An alternative to rationing. Arch Intern Med 1988, 148(6):1403-1405.

16. Byrick RJ, Mazer CD, Caskennette GM, Closure of an intermediate care unit. Impact on critical care utilization. Chest 1993, 104(3):876-881.

17. Luce JM, Improving the quality and utilization of critical care. QRB Qual Rev Bull 1991, 17(2):42-47.

18. Cheng DC, Byrick RJ, Knobel E, Structural models for intermediate care areas. Crit Care Med 1999, 27(10):2266-2271.

19. Arabi Y, Venkatesh S, Haddad S, Al Malik S, Al Shimemeri A, The characteristics of very short stay ICU admissions and implications for optimizing ICU resource utilization: the Saudi experience. Int J Qual Health Care 2004, 16(2):149-155.

20. Ryan DW, Bayly PJ, Weldon OG, Jingree M, A prospective twomonth audit of the lack of provision of a high-dependency unit and its impact on intensive care. Anaesthesia 1997, 52(3):265270.

21. Eachempati SR, Hydo LJ, Barie PS, The effect of an intermediate care unit on the demographics and outcomes of a surgical intensive care unit population. Arch Surg 2004, 139(3):315-319.

22. Bertolini G, Confalonieri M, Rossi C, Rossi G, Simini B, Gorini M, Corrado A: Costs of the COPD. Differences between intensive care unit and respiratory intermediate care unit. Respir Med 2005, 99(7):894-900.

23. Keenan SP, Massel D, Inman KJ, Sibbald WJ, A systematic review of the cost-effectiveness of noncardiac transitional care units. Chest 1998, 113(1):172-177.

24. Krieger BP, Ershowsky P, Spivack D, One year's experience with a noninvasively monitored intermediate care unit for pulmonary patients. JAMA 1990, 264(9):1143-1146.

25. Rudy EB, Daly BJ, Douglas S, Montenegro HD, Song R, Dyer MA, Patient outcomes for the chronically critically ill: special care unit versus intensive care unit. Nurs Res 1995, 44(6):324-331.

26. Patterson PA, Elpern EH, Silver MR, Advances in patient care management: the NRCU. Crit Care Nurse 1991, 11(9):42-45.

27. Douglas S, Daly B, Rudy E, Song R, Dyer MA, Montenegro $H$, The cost-effectiveness of a special care unit to care for the chronically critically ill. J Nurs Adm 1995, 25(11):47-53.

28. Elpern EH, Silver MR, Rosen RL, Bone RC, The noninvasive respiratory care unit. Patterns of use and financial implications. Chest 1991, 99(1):205-208.

29. Singer M, Myers S, Hall G, Cohen SL, Armstrong RF, The cost of intensive care: a comparison on one unit between 1988 and 1991. Intensive Care Med 1994, 20(8):542-549.

30. Porath A, Reuveni H, Grinberg G, Lieberman D, The intermediate care unit as a cost-effective option for the treatment of medical patients in critical condition. Isr J Med Sci 1995, 31(11):674-680.

31. Dawson S, Runk JA, Right patient? Right bed? A question of appropriateness. AACN Clin Issues 2000, 11(3):375-385.

32. Vitacca M, Clini E, Scalvini S, Foglio K, Quadri A, Levi G:
Cardiopulmonary intermediate intensive unit: time course of two years activity. Monaldi Arch Chest Dis 1993, 48(4):296300.

33. Durbin CG, Jr., Kopel RF, A case-control study of patients readmitted to the intensive care unit. Crit Care Med 1993, 21(10):1547-1553.

34. Rosenberg AL, Watts C, Patients readmitted to ICUs* : a systematic review of risk factors and outcomes. Chest 2000, 118(2):492-502.

35. Le Gall JR, Loirat P, Alperovitch A, Glaser P, Granthil C, Mathieu D et al, A simplified acute physiology score for ICU patients. Crit Care Med 1984, 12(11):975-977.

36. Knaus WA, Draper EA, Wagner DP, Zimmerman JE, APACHE II: a severity of disease classification system. Crit Care Med 1985, 13(10):818-829.

37. Knaus WA, Zimmerman JE, Wagner DP, Draper EA, Lawrence DE, APACHE-acute physiology and chronic health evaluation: a physiologically based classification system. Crit Care Med 1981, 9(8):591-597.

38. Lemeshow S, Teres D, Pastides H, Avrunin JS, Steingrub JS, A method for predicting survival and mortality of ICU patients using objectively derived weights. Crit Care Med 1985, 13(7):519-525.

39. Teres $D$, Lemeshow $S$, Avrunin JS, Pastides $H$, Validation of the mortality prediction model for ICU patients. Crit Care Med 1987, 15(3):208-213.

40. Knaus WA, Wagner DP, Draper EA, Zimmerman JE, Bergner M, Bastos PG, et al: The APACHE III prognostic system. Risk prediction of hospital mortality for critically ill hospitalized adults. Chest 1991, 100(6):1619-1636.

41. Auriant I, Vinatier I, Thaler F, Tourneur M, Loirat P, Simplified acute physiology score II for measuring severity of illness in intermediate care units. Crit Care Med 1998, 26(8):1368-1371.

42. Ip SP, Leung YF, Ip CY, Mak WP, Outcomes of critically ill elderly patients: is high-dependency care for geriatric patients worthwhile? Crit Care Med 1999, 27(11):2351-2357.

43. Torres OH, Francia E, Longobardi V, Gich I, Benito S, Ruiz D, Short- and long-term outcomes of older patients in intermediate care units. Intensive Care Med 2006, 32(7):1052-1059.

44. Zimmerman JE, Wagner DP, Draper EA, Knaus WA, Improving intensive care unit discharge decisions: supplementing physician judgment with predictions of next day risk for life support. Crit Care Med 1994, 22(9):1373-1384.

45. Bone RC, McElwee NE, Eubanks DH, Gluck EH, Analysis of indications for early discharge from the intensive care unit. Clinical efficacy assessment project: American College of Physicians. Chest 1993, 104(6):1812-1817.

46. Mahoney FI, Barthel DW, Functional Evaluation: The Barthel Index. Md State Med J 1965, 14:61-65.

47. Charlson ME, Pompei $P$, Ales $K L$, MacKenzie $C R$, A new method of classifying prognostic comorbidity in longitudinal studies: development and validation. J Chronic Dis 1987, 40(5):373-383. 
48. Miranda DR, de Rijk A, Schaufeli W, Simplified Therapeutic Intervention Scoring System: the TISS-28 items--results from a multicenter study. Crit Care Med 1996, 24(1):64-73.

49. Miranda DR, Nap R, de Rijk A, Schaufeli W, lapichino G, Nursing activities score. Crit Care Med 2003, 31(2):374-382.

50. Bo M, Massaia M, Raspo S, Bosco F, Cena P, Molaschi M et al, Predictive factors of in-hospital mortality in older patients admitted to a medical intensive care unit. J Am Geriatr Soc 2003, 51(4):529-533

51. Pirret AM, Utilizing TISS to differentiate between intensive care and high-dependency patients and to identify nursing skill requirements. Intensive Crit Care Nurs 2002, 18(1):19-26

52. Hood E, Bhangu A, Pandit D, Michael A, Is age a predictor of mortality in a UK medical high dependency unit? $\mathrm{Br} J$ Anaesth 2011, 107(2):186-192.

53. Nelson LM, Longstreth WT, Jr. Koepsell TD, van Belle G, Proxy respondents in epidemiologic research. Epidemiol Rev 1990, 12:71-86.

54. Mundt DJ, Gage RW, Lemeshow S, Pastides H, Teres D, Avrunin JS, Intensive care unit patient follow-up. Mortality, functional status, and return to work at six months. Arch Intern Med 1989, 149(1):68-72.

55. Bion J, Outcomes in intensive care. BMJ 1993, 307(6910):953954.

56. Capuzzo M., Volta C.A., Moreno R.P., Valentin A., Guidet B., Lapichino $G$. et al, Hospital mortality of adults admitted to Intensive Care Units in hospitals with or without Intermediate care Units: a multicentre European Cohort study. Critical Care 2014, 18:551.

\section{Comment on this article:}

\section{$4 B$ in $8+8$}

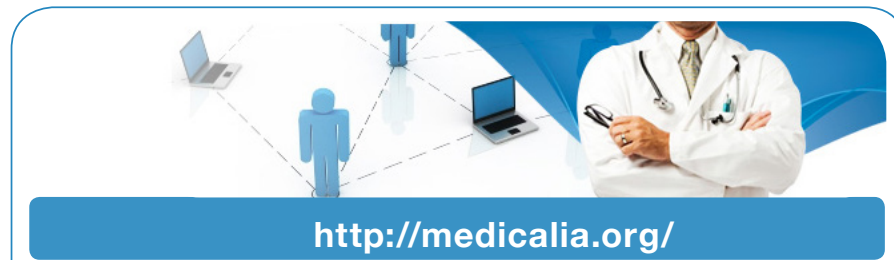

Where Doctors exchange clinical experiences, review their cases and share clinical knowledge. You can also access lots of medical publications for free. Join Now!

\section{Publish with iMedPub}

\section{http://www.imed.pub}

International Archives of Medicine is an open access journal publishing articles encompassing all aspects of medical science and clinical practice. IAM is considered a megajournal with independent sections on all areas of medicine. IAM is a really international journal with authors and board members from all around the world. The journal is widely indexed and classified Q1 in category Medicine. 